\title{
LASER PHOTOCOAGULATION FOR PROLIFERATIVE RETINOPATHY IN SICKLE HAEMOGLOBIN C DISEASE
}

\author{
PETER D. FOX, KYRA MINNINGER, MARK L. FORSHAW, S. J. RUPERT VESSEY, \\ JOANNE S. MORRIS and GRAHAM R. SERJEANT
}

Jamaica

\begin{abstract}
SUMMARY
The effect of sectoral, scatter laser photocoagulation on proliferative sickle retinopathy (PSR) was investigated by reviewing fluorescein angiograms of 88 sickle cellhaemoglobin $C$ patients enrolled in a controlled, randomised trial. Follow-up was for a median period of 2.9 years. Complete infarction of all PSR in an eye occurred in 7 of 74 treated eyes and 2 of 60 control eyes. Treatment resulted in significantly greater regression (decrease in number or size of PSR lesions) in eyes of patients aged $<25$ years at enrolment but not in eyes of patients $\geqslant 25$ years at enrolment. Infarction of individual PSR lesions was significantly more common in treated eyes. Treated PSR was significantly more likely to infarct if small $\left(<15^{\circ}\right.$ circumferential involvement) and if flat rather than elevated. New PSR was significantly less likely to develop in treated eyes.
\end{abstract}

Proliferative sickle retinopathy (PSR) may be complicated by vitreous haemorrhage and retinal detachment. ${ }^{1}$ Treatment modalities advocated to prevent the blinding complications of PSR have included diathermy, ${ }^{2}$ cryotherapy ${ }^{3}$ and feeder vessel coagulation. ${ }^{4}$ PSR regression has been reported following uncontrolled studies of sectoral $^{5}$ and circumferential ${ }^{6}$ scatter laser photocoagulation. A controlled, randomised trial of sectoral, scatter laser photocoagulation for PSR has demonstrated a significant reduction in visual loss in treated eyes. ${ }^{7}$ This study reports the effect of laser photocoagulation on PSR behaviour in sickle cell-haemoglobin C (SC) patients participating in that trial.

\section{PATIENTS AND METHODS}

Patients attending the Sickle Cell Clinic at the University of the West Indies were invited to participate in a controlled, randomised study of sectoral, scatter laser photocoagulation for perfused PSR. ${ }^{7}$ Informed consent was obtained

From: Medical Research Council Laboratories (Jamaica), University of the West Indies.

Correspondence to: Graham R. Serjeant, FRCP, MRC Laboratories, University of West Indies, Mona, Kingston 7, Jamaica. from all patients prior to enrolment. The majority of the patients in the trial had SC disease and to avoid differences in behaviour between genotypes only SC eyes were compared in this study. Eyes with cataract or vitreous haemorrhage that would have prevented laser photocoagulation were excluded from the study, as were eyes with retinal detachment, previous photocoagulation, ocular surgery and eyes that had participated in previous studies of feeder vessel photocoagulation. ${ }^{8,9}$ Patients with diabetes mellitus or systemic hypertension were also excluded. Patients with unilateral PSR or with only one eligible eye were randomly assigned to treatment or control groups (ratio $2: 1$ by computer-generated randomisation). If the second eye subsequently developed PSR or if vitreous haemorrhage cleared then it received the opposite modality. Patients with bilateral PSR had the right eye randomised; the left eye received the opposite modality.

The size and elevation of the PSR lesion was documented at each visit, a small lesion being defined as $<15^{\circ}$ circumferential involvement. Treated eyes had blue/green argon laser (Britt 3250) burns $500 \mu \mathrm{m}$ in diameter, $0.1 \mathrm{~s}$ duration, placed around the PSR lesion. Treatment extended $1 \mathrm{~mm}$ anterior and posterior and 1 clock hour each side of the lesion (Figs. 1, 2) and sufficient power was used to produce mild whitening of the retina. The number of burns used depended on the size of the PSR lesion. Subsequent behaviour was assessed by serial fluorescein angiograms performed at 6 monthly intervals. Regression of proliferative disease was defined as a decrease in size or number of PSR lesions on angiography. Survival curve analysis was used to compare behaviour (regression) between treated and control eyes and differences were assessed by the logrank test. Logistic regression analysis, which allowed for different lengths of follow-up between eyes, was used to compare the frequency of development of new PSR lesions and differences were assessed by the $\chi^{2}$ test. For the purpose of this analysis, all patients with both eyes entered in to the trial at any time were considered to be bilateral cases. 


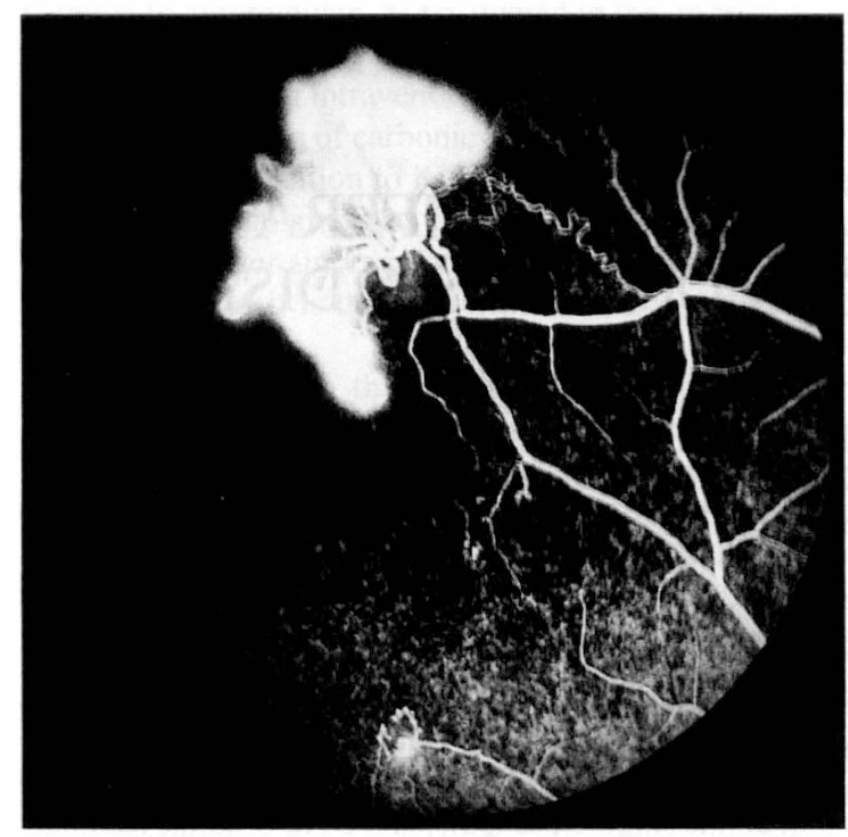

Fig. 1. Fluorescein angiogram of a small, elevated PSR lesion in a SC male prior to laser photocoagulation.

\section{RESULTS}

A total of 88 SC patients (134 eyes) were reviewed. There were 46 bilateral and 42 unilateral cases. Of the 46 bilateral cases, 16 had unilateral PSR when initially enrolled but during the study period PSR developed in the fellow eye, which then entered the trial. The remaining 30 bilateral cases had bilateral PSR when first enrolled. Of the 42 unilateral cases, 20 ( 15 treated, 5 control) had unilateral PSR and 22 (13 treated, 9 control) had bilateral PSR but only one eye was eligible for entry in to the trial. Of these 22 unilateral cases, 15 ( 7 treated, 8 control) had PSR in the fellow eye which had previously been treated, 2 ( 1 treated, 1 control) had spontaneously non-perfused PSR in the fel-

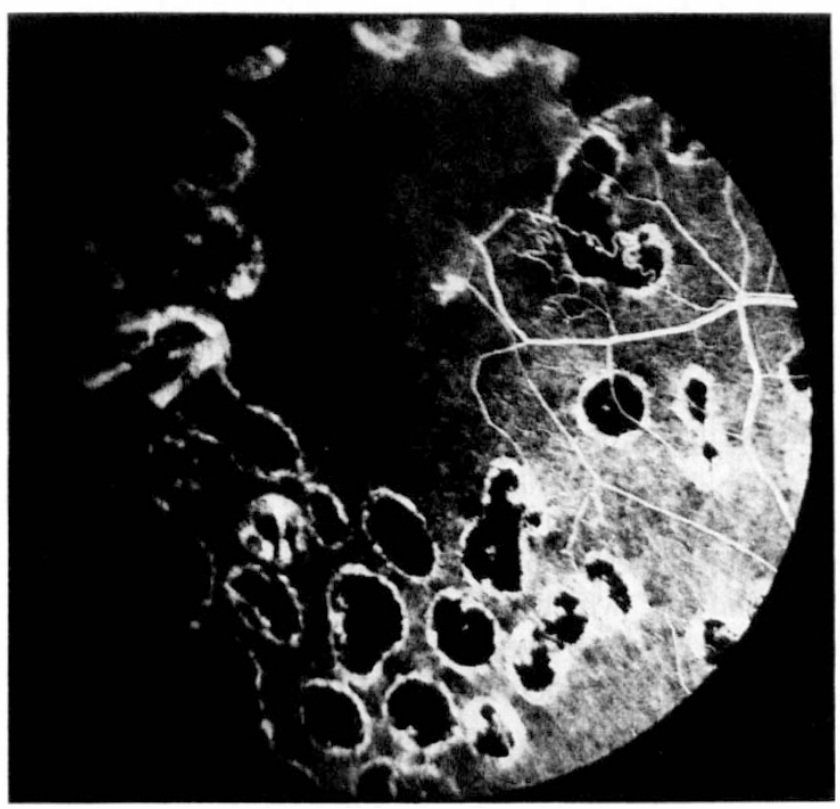

Fig. 2. PSR regression following sectoral, scatter laser photocoagulation. low eye, 4 (treated) had a retinal detachment in the fellow eye and 1 (treated) had vitreous haemorrhage in the fellow eye.

A total of 74 treated SC eyes and 60 control SC eyes were observed for a median period of 2.9 years (range $0.1-7.2$ years). At enrolment 30 of 74 treated eyes and 25 of 60 control eyes were in patients aged $<25$ years. At the initial examination 237 of 328 (72\%) PSR lesions were small ( $<15^{\circ}$ circumferential involvement) and 127 of 328 (39\%) were flat. During the study a further 92 PSR lesions developed. Table I shows the number of PSR lesions present in treated and control eyes at the end of the study. Treated eyes contained 174 small and 59 large PSR lesions at the end of the study, of which 104 were flat and 129 were elevated. Control eyes contained 153 small and 34 large PSR lesions at the end of the study, of which 95 were flat and 92 were elevated. There were no significant differences between treated and control eyes in the number, size and type of PSR lesions. Follow-up of control eyes revealed no significant age or sex difference in regression of PSR.

Treated and control eyes were then compared. Only 7 of 74 treated eyes and 2 of 60 control eyes had no perfused PSR lesions at the last visit $\left(\chi^{2}=0.95, p=0.3\right)$. Treated eyes had more PSR regression (decrease in size or number of PSR lesions on angiography) than control eyes, but this effect was only significant in patients aged $<25$ years at enrolment $\left(\chi^{2}=11.5, p<0.001\right)$, not in older patients $\left(\chi^{2}=0.25, p=0.6\right)$.

Analysis of the behaviour of individual PSR lesions revealed significantly more infarction in treated eyes $\left(\chi^{2}=12.7, p<0.001\right)$ (Fig. 3). Of the treated PSR lesions, infarction occurred more frequently if the lesions were small $\left(\chi^{2}=16.4, p<0.001\right)$ and if they were flat rather than elevated $\left(\chi^{2}=20.5, p<0.001\right)$.

During follow-up, new PSR lesions developed in 25 of $74(34 \%)$ treated eyes and 35 of $60(58 \%)$ control eyes. Using logistic regression analysis, significantly fewer new lesions developed in treated eyes $\left(\chi^{2}=9.9, p=0.002\right)$. In treated eyes most new PSR lesions developed circumferential to the treated areas. PSR developed within the treatment area in only 2 eyes and posterior to the treatment area in 3 eyes. There were no complications attributable to scatter laser photocoagulation.

Table I. Comparison of the number of PSR lesions per eye in treated and control eyes at the end of the study

\begin{tabular}{lcc}
\hline & $\begin{array}{c}\text { Unilateral } \\
\text { entry }\end{array}$ & $\begin{array}{c}\text { Bilateral } \\
\text { entry }\end{array}$ \\
\hline Treated eyes & & \\
Mean & 2.8 & 3.4 \\
SD & 2.1 & 1.7 \\
Range & $1-8$ & $1-7$ \\
Eyes & 28 & 46 \\
Control eyes & & \\
Mean & 2.7 & 3.2 \\
SD & 1.1 & 1.7 \\
Range & $1-5$ & $1-8$ \\
Eyes & 14 & 46 \\
\hline
\end{tabular}




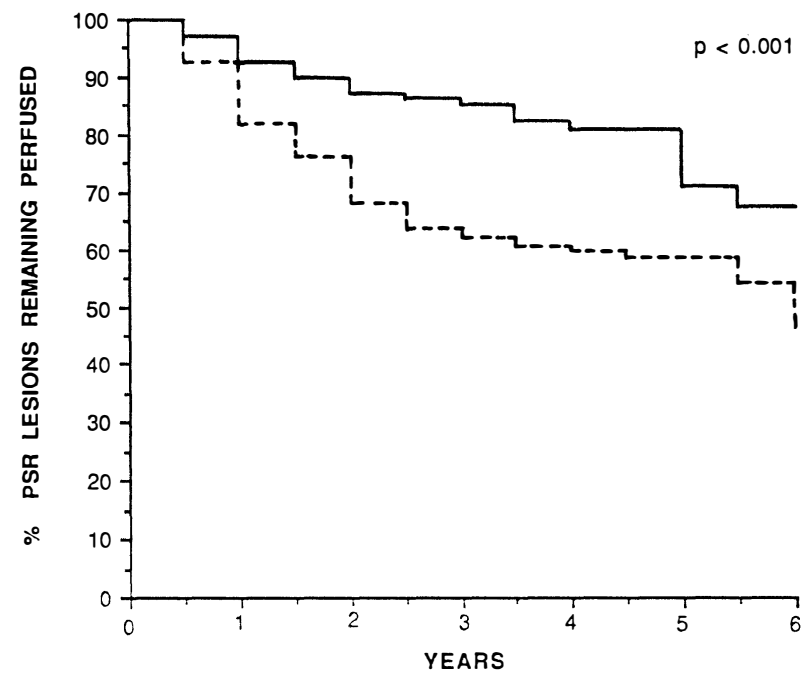

Fig. 3. Survival curve analysis of individual PSR lesions in treated eyes (broken line) and control eyes (continuous line).

\section{DISCUSSION}

Feeder vessel coagulation has been shown to be highly effective in achieving closure of PSR. ${ }^{8}$ However, complications of this treatment included choroidal neovascularisation, ${ }^{10}$ vitreous haemorrhage, ${ }^{11}$ and tractional ${ }^{12}$ and rhegmatogenous ${ }^{9}$ retinal detachments. These complications have led most investigators to abandon feeder vessel coagulation and to consider other modes of treatment. The finding that photocoagulation of areas of capillary non-perfusion resulted in regression of proliferative diabetic retinopathy ${ }^{13}$ led to this technique being applied to PSR. Sickle retinopathy is characterised by peripheral vaso-occlusion and the subsequent development of proliferative retinopathy, usually at the venous end of arteriovenous shunts. As well as complete vascular closure anterior to the PSR there is loss of capillary network just posterior to the PSR lesion and it was this junctional ischaemic area that was chosen for treatment. The regression of PSR observed following laser supports the concept that ischaemia in this area is responsible for vasoproliferation. The reduction in the number of new PSR lesions developing following treatment suggests that sectoral laser was sufficient to reduce the ischaemic stimulus.

In a study of 21 eyes with proliferative retinopathy treated with sectoral, scatter laser photocoagulation, regression of 24 of 28 flat new vessel lesions and 4 of 17 elevated lesions was reported. ${ }^{5}$ However, the series included 5 patients with sickle cell trait, of which 1 also had diabetes and 1 had sarcoidosis. Subsequently the effect of $360^{\circ}$ peripheral circumferential scatter photocoagulation on PSR was described. ${ }^{6}$ In a series of 70 eyes with 220 new vessel lesions, $33 \%$ regressed completely and $46 \%$ regressed partially following treatment. Neither series was controlled and in both, patients of more than one genotype were studied. Spontaneous PSR regression has been well documented ${ }^{14}$ and auto-infarction has been reported to be more common in homozygous sickle cell disease than SC disease..$^{15}$ It was therefore important that these techniques were subjected to controlled, randomised trials and that comparison between genotypes was avoided.

It might be argued that the regression of PSR observed in this study was in part due to an excess of treated eyes in unilateral cases. However, only 20 of the $88 \mathrm{SC}$ patients analysed had unilateral PSR throughout the study and there was no significant difference between treated and control groups in the number, size or type of PSR. We therefore concluded that the control and treatment groups were comparable and that the highly significant differences in PSR regression were valid.

This controlled study has demonstrated that sectoral, scatter laser photocoagulation induced regression of early PSR in patients with SC disease. Established PSR, especially in older patients, was less likely to respond. PSR has been observed in up to $70 \%$ of SC patients àged $>40$ years; ${ }^{16}$ however, permanent visual loss was found to be uncommon. ${ }^{17}$ Assuming that PSR regression is necessary to prevent visual loss, then large numbers of patients with early disease need to be treated to prevent visual loss. Many of these patients would be treated unnecessarily. Further studies of the natural history of PSR are needed to determine the risk factors for visual loss.

Key words: Laser photocoagulation, Proliferative retinopathy, Sickle cell disease.

\section{REFERENCES}

1. Goldberg MF. Classification and pathogenesis of proliferative sickle retinopathy. Am J Ophthalmol 1971;71: 649-65.

2. Hannon JF. Vitreous haemorrhages associated with sickle cell-hemoglobin C disease. Am J Ophthalmol 1956;42: 707-12.

3. Lee CB, Woolf MB, Galinos SO, Goldbaum MH, Stevens TS, Goldberg MF. Cryotherapy of proliferative sickle retinopathy. I. Single freeze thaw cycle. Ann Ophthalmol 1975;7:1299-308.

4. Goldberg MF. Treatment of proliferative sickle retinopathy. Trans Am Acad Ophthalmol Otol 1971;75:532-56.

5. Rednam KRV, Jampol LM, Goldberg MF. Scatter retinal photocoagulation for proliferative sickle retinopathy. Am J Ophthalmol 1982;93:594-9.

6. Kimmel AS, Magaral LE, Stephens RF, Cruess AF. Peripheral circumferential retinal scatter photocoagulation for the treatment of proliferative sickle retinopathy. Ophthalmology 1986;93:1429-34.

7. Farber MD, Jampol LM, Fox PD, Moriarty BJ, Acheson RW, Rabb MF, Serjeant GR. A randomised clinical trial of scatter photocoagulation for proliferative sickle retinopathy. Arch Ophthalmol 1991;109:363-7.

8. Condon PI, Serjeant GR. Photocoagulation and diathermy in the treatment of proliferative sickle retinopathy. $\mathrm{Br} \mathrm{J}$ Ophthalmol 1974;58:650-62.

9. Galinos SO, Asdourian GK, Woolf MB, Goldberg MF, Busse BJ. Choroido-vitreal neovascularisation after argon laser photocoagulation. Arch Ophthalmol 1975;93: 524-30.

10. Condon PI, Jampol LM, Ford SM, Serjeant GR. Choroidal neovascularisation induced by photocoagulation in sickle cell disease. Br J Ophthalmol 1981;65:192-7.

11. Dizon-Moore RV, Jampol LM, Goldberg MF. Chorioretinal 
and choriovitreal neovascularisation. Arch Ophthalmol 1981;99:842-9.

12. Jampol LM, Condon PI, Farber M, Rabb M, Ford S, Serjeant GR. A randomised clinical trial of feeder vessel photocoagulation of proliferative sickle retinopathy. I. Preliminary results. Ophthalmology 1983;90:541-5.

13. The Diabetic Retinopathy Study Research Group. Preliminary reports on effects of photocoagulation therapy. Am J Ophthalmol 1976;81:383-96.

14. Nagpal KC, Patrianakos D, Asdourian GK, Goldberg MF,
Rabb M, Jampol LM. Spontaneous regression (autoinfarction) of proliferative sickle retinopathy. Am J Ophthalmol 1975;80:885-92.

15. Condon PI, Serjeant GR. Behaviour of untreated proliferative sickle retinopathy. Br J Ophthalmol 1980;64:404-11.

16. Fox PD, Dunn DT, MorrisJS, Serjeant GR. Risk factors for proliferative sickle retinopathy. Br JOphthalmol 1990;74:172-6.

17. Moriarty BJ, Acheson RW, Condon PI, Serjeant GR. Pattems of visual loss in untreated sickle cell retinopathy. Eye $1988 ; 2: 330-5$ 